\title{
Evaluation of ECMWF ERA-40 temperature and wind in the lower tropical stratosphere since 1988 from past long-duration balloon measurements
}

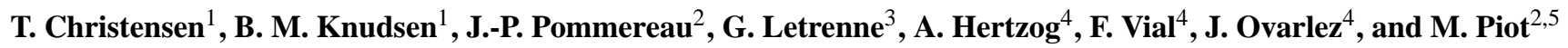 \\ ${ }^{1}$ Danish Meteorological Institute, Copenhagen, Denmark \\ ${ }^{2}$ Service d'Aéronomie, IPSL/CNRS, Verrières-Le-Buisson, France \\ ${ }^{3}$ Centre National d'Études Spatiales, Toulouse, France \\ ${ }^{4}$ Laboratoire de Météorologie Dynamique, IPSL/CNRS, Palaiseau, France \\ ${ }^{5}$ Institut für Umweltphysik, University of Heidelberg, Heidelberg, Germany
}

Received: 1 February 2007 - Published in Atmos. Chem. Phys. Discuss.: 5 March 2007

Revised: 8 June 2007 - Accepted: 12 June 2007 - Published: 2 July 2007

\begin{abstract}
The temperature and wind of the ECMWF ERA40 reanalysis in the tropical lower stratosphere during the period 1988-2001 has been evaluated by comparison with independent in situ measurements of 21 IR Montgolfier and superpressure long-duration balloon flights performed by CNES from Pretoria $\left(26^{\circ} \mathrm{S}\right)$ in South Africa in 1988-1989, Latacunga $\left(1^{\circ} \mathrm{S}\right)$ in Ecuador in 1991-1998 and Bauru $\left(22^{\circ} \mathrm{S}\right)$ in Brazil in 2000-2001. The ERA-40 temperature displays a bias varying progressively from $+1.16 \mathrm{~K}$ in $1988-1989$, to $+0.26 \mathrm{~K}$ in $1994-1996$ and $-0.46 \mathrm{~K}$ after 1998 , the latter being fully consistent with recent evaluations of ECMWF operational analysis from radio occultation and in situ longduration balloon observations. The amplitude of the bias and its evolution are very similar to the results of a previous evaluation from radiosondes in 1991-2003, suggesting that the origin of the drift of ERA-40 might be mainly due to errors in the series of satellite measurements of MSU, replaced by AMSU in 1998, assimilated in the model.

The ERA-40 zonal wind speed in the lower stratosphere appears slightly overestimated by $0.7-1.0 \mathrm{~m} / \mathrm{s}$ on average in both the tropics and equatorial region, that is by $5-10 \%$ compared to the average $10-20 \mathrm{~m} / \mathrm{s}$ wind speed. This bias, fully consistent with a recent evaluation of ECMWF operational analysis in 2004, is found constant during the whole 19882001 period, suggesting a shortfall in the variabililty of ERA40 horizontal winds in the lower stratosphere in the tropics and the equatorial region. Finally calculated trajectories using ERA-40, frequently used for analysing field observa-
\end{abstract}

Correspondence to: $\mathrm{T}$. Christensen

(tic@dmi.dk) tions, are found in error compared to that of the balloons by $\pm 500 \mathrm{~km}$ after 5 days and $\pm 1000 \mathrm{~km}$ after 10 days.

\section{Introduction}

Historical reanalyses such as the European Centre for Medium-Range Weather Forecasts 40-year reanalysis (ECMWF ERA-40) are widely used, from research in climate and atmosphere to ecosystems and health.

In stratospheric research, reanalysis data are used for various purposes, e.g. influence of temperature on photochemical reaction rates or wind data in chemistry transport models, but most important for studying the past evolution of the stratosphere is the long-term change of temperature and winds. However, although reanalyses capture the cooling of the stratosphere, the amplitude of the trend may be quite different from that derived from radiosondes or satellite observations, already different between themselves, for reasons difficult to assess (Karl et al., 2006). As an example, between 100 and $50 \mathrm{hPa}$ between $10^{\circ} \mathrm{S}$ and $10^{\circ} \mathrm{N}$, the trend since 1979 could vary from between -0.69 and $-0.64 \mathrm{~K} /$ decade in the radiosondes depending on the evaluation, to between -0.37 and $-0.29 \mathrm{~K} /$ decade for the satellites and $-0.83 \mathrm{~K} /$ decade for NCEP and only $-0.005 \mathrm{~K} /$ decade for ERA-40, while the causes for these discrepancies are not clearly identified.

Evaluations of the accuracy of the reanalyses are thus important, but, especially for the stratospheric part, are not easy, since observations are sparse and operational data, like those from radiosondes and certain satellites, are already assimilated in the analyses. Even though reanalyses are designed

Published by Copernicus Publications on behalf of the European Geosciences Union. 
to be as homogeneous a data set as possible, the atmospheric observation network is constantly changing, and consequently, so is the reanalysis accuracy. A data set which is new to ERA-40, especially a data set covering the data sparse stratosphere of the tropics, as the balloon data from past campaigns presented in this work, can add significant information.

There are very few comparisons of ERA-40 stratospheric temperatures in the tropics and in addition mostly restricted to the $100 \mathrm{hPa}$ or tropopause level. By comparing modelled temperatures to radiosondes at $100 \mathrm{hPa}$ in the equatorial region between $10^{\circ} \mathrm{N}-10^{\circ} \mathrm{S}$ in 1991-2002, Randel et al. (2004) indicate (their Fig. 11) a drop in deseasonalized temperature anomalies from about $+0.5 \mathrm{~K}$ to $-0.5 \mathrm{~K}$ of ERA40 after 1998 and onwards compared to 1991-1997, amplified to $2-3 \mathrm{~K}$ after 2001 in NCEP/NCAR and the METO analysis of the UK Met Office, but not in ERA-40. Though the cause of the drops was not clearly identified, the authors note that a potentially important change occurred with the introduction in NCEP and METO of temperature retrievals of ATOVS satellite measurements in July 2001. From comparisons with global radio occultation (RO) temperature measurements during two and half years from March 2002 to August 2004, Gobiet et al. (2005) are concluding at an excellent agreement within $\pm 1 \mathrm{~K}$ on average with ECMWF in the lower stratosphere, but a systematic cold bias of up to $2 \mathrm{~K}$ in a narrow layer at the altitude of the tropopause, attributed to the different vertical resolution of the analyses $(>1.3 \mathrm{~km})$ and the RO measurements of $1 \mathrm{~km}$ at that altitude. Finally, the last piece of information available is the comparison between the HIBISCUS balloons and ECMWF in 2004, displaying an average cold bias of $-0.9 \pm 1.3 \mathrm{~K}$ (Knudsen et al., 2006).

Similarly, there are few wind comparisons available. Baldwin and Gray (2005) made monthly mean comparisons with rawinsondes (assimilated in the model) and rocket sondes (not assimilated). For the rawinsondes at $10-70 \mathrm{hPa}$, the agreement found is very good from the late 1980's and onwards, with an RMS error of less than $1.4 \mathrm{~m} / \mathrm{s}$ after 1985 and less than $1.0 \mathrm{~m} / \mathrm{s}$ after 1995 . For the rocketsondes a correlation exceeding 0.95 was found when comparing ERA-40 to de-seasonalized data from the period 1965-1983 at 10$30 \mathrm{hPa}$, while a correlation exceeding 0.5 was found up to $2-3 \mathrm{hPa}$. Another comparison available is that of Knudsen et al. (2006) with the data of the HIBISCUS balloon flights in 2004 displaying a positive bias of ECMWF of $0.7 \mathrm{~m} / \mathrm{s}$ (wind too strong) for the ECMWF zonal wind in the tropics, a negligible difference for the meridional wind and an average trajectory error of $500 \mathrm{~km}$ after 5 days.

In the frame of the HIBISCUS project, dedicated in part to an assessment of the quality of meteorological models (Pommereau et al., 2007), the historical records of long-duration IR Montgolfier and superpressure constant-level balloons launched in the tropics since 1988 were digitized. In this paper the newly digitized past balloon data are used to evalu- ate the accuracy of the ECMWF ERA-40 reanalysis temperatures, horizontal winds and trajectories in the tropical lower stratosphere and tropopause region. The method is described by Pommereau et al. (2002) and Knudsen et al. (2002) who studied the winter Arctic vortex.

The originality of this study is three-fold: the use of real data which is not assimilated in the re-analysis; data which stems from the sparsely observationally sampled tropical, lower stratosphere, and data which has a resolution sufficient to contain most of the variability of that region.

The focus of this paper is on ECMWF ERA-40 and the lower stratosphere. This work can be seen as part of the general and important study aimed at assessing the accuracy of meteorological analyses and reanalyses.

The paper is outlined as follows: Section 2 presents the long-duration balloon flights and describes the data collection and the accuracy of the temperature measurements and the position data for winds and trajectories. Finally that section presents briefly the main characteristics of the ECMWF ERA-40 data used in this paper. Sections 3, 4 and 5 describe the results of the evaluation of ECMWF ERA-40 temperature, horisontal wind and trajectories, respectively, and compare the results to the work of other authors. The last section summarizes the results and conclusions of this study.

\section{Data}

\subsection{Past long-duration balloon flights}

639 long-duration balloon flights have been carried out by the French Centre National d'Etudes Spatiales (CNES) for a variety of projects: small constant level super-pressure balloons (SPB) at $200 \mathrm{hPa}$ and $100 \mathrm{hPa}$ between 1966-1979, followed by Infra-Red Montgolfier (MIR) since 1981, and more recently $10 \mathrm{~m}$ diameter SPB since 1998 . But, with the exception of the 480 balloons flown at $200 \mathrm{hPa}$ in the Southern Hemisphere in 1971-1972 whose data were collected by a dedicated EOLE satellite (Hertzog et al., 2006), the limited data transmitted by simple HF systems, moreover handled manually, could not be recovered. Only data after 1988 archived on various media could be available.

For the $30 \mathrm{MIR}$ and 3 SPB flights which were performed in the tropics between 1988 and 2001, reliable data could be recovered for 18 MIR and 3 SPB launches. The whole set of flights is listed in Table 1 as 24 flights, but three of these were separate payloads on the same balloon.

The balloons were launched from three different sites: Pretoria in South Africa $\left(25.73^{\circ} \mathrm{S}, 28.18^{\circ} \mathrm{E}\right)$ and Bauru in Brazil $\left(22.36^{\circ} \mathrm{S}, 49.03^{\circ} \mathrm{W}\right)$ in the tropics in the stratospheric easterlies of the austral summer season, and at Latacunga in Equador $\left(0.91^{\circ} \mathrm{S}, 78.62^{\circ} \mathrm{W}\right)$ where the wind direction and speed depend on the phase of the Quasi Biennial Oscillation (QBO). The balloons used were MIR of 36000 or $45000 \mathrm{~m}^{3}$ volume and SPB of $10 \mathrm{~m}$ diameter. MIR (see e.g. Pom- 
Table 1. List of long-duration balloon flights. The launch date is given in the format yyyymmdd (first four digits is the year, the next two digits is the month and the last two is the day of the month). Three flights in 2001 were separate payloads launched on the same balloon.

\begin{tabular}{|c|c|c|c|c|c|c|c|c|c|}
\hline \multicolumn{2}{|c|}{ Launch } & \multicolumn{2}{|c|}{ Instrumentation } & \multirow{2}{*}{$\begin{array}{r}\text { Duration } \\
\text { Days }\end{array}$} & \multicolumn{5}{|c|}{ Number of data points } \\
\hline Site & Date & Balloon & Payload & & $\mathrm{T}$ & $\mathrm{u}$ & $\mathrm{v}$ & Traj. & Loc. \\
\hline Pretoria & 19881113 & MIR 36 & Samba & 45 & 2815 & 280 & 279 & 524 & 176 \\
\hline Pretoria & 19881119 & MIR 36 & Samba & 29 & 2413 & 0 & 0 & 240 & 62 \\
\hline Pretoria & 19881202 & MIR 36 & Samba & 25 & 2547 & 1178 & 1181 & 255 & 90 \\
\hline Pretoria & 19881208 & MIR 36 & Samba & 53 & 1557 & 1556 & 1548 & 609 & 155 \\
\hline Pretoria & 19891113 & MIR 36 & $\mathrm{Samba} / \mathrm{H}_{2} \mathrm{O}$ & 12 & 2746 & 2444 & 2444 & 137 & 53 \\
\hline Pretoria & 19891112 & MIR 36 & Samba & 51 & 691 & 827 & 827 & 188 & 59 \\
\hline Pretoria & 19891123 & MIR 36 & $\mathrm{Samba} / \mathrm{H}_{2} \mathrm{O}$ & 9 & 1283 & 472 & 472 & 0 & 40 \\
\hline Latacunga & 19910403 & MIR 36 & $\mathrm{Samba} / \mathrm{H}_{2} \mathrm{O}$ & 20 & 615 & 532 & 557 & 226 & 192 \\
\hline Latacunga & 19940114 & MIR 45 & $\mathrm{Samba} / \mathrm{H}_{2} \mathrm{O}$ & 41 & 1727 & 339 & 340 & 486 & 185 \\
\hline Latacunga & 19940118 & MIR 45 & $\mathrm{Samba} / \mathrm{H}_{2} \mathrm{O}$ & 8 & 159 & 25 & 24 & 0 & 76 \\
\hline Latacunga & 19940123 & MIR 45 & $\mathrm{Samba} / \mathrm{H}_{2} \mathrm{O}$ & 9 & 253 & 46 & 49 & 0 & 34 \\
\hline Latacunga & 19940128 & MIR 45 & $\mathrm{Samba} / \mathrm{H}_{2} \mathrm{O}$ & 7 & 158 & 41 & 42 & 0 & 16 \\
\hline Latacunga & 19940203 & MIR 45 & $\mathrm{Samba} / \mathrm{H}_{2} \mathrm{O}$ & 12 & 0 & 68 & 94 & 0 & 136 \\
\hline Latacunga & 19960328 & MIR 45 & Samba & 14 & 2437 & 896 & 898 & 0 & 896 \\
\hline Latacunga & 19960405 & MIR 45 & Samba & 24 & 5977 & 1948 & 1958 & 268 & 1948 \\
\hline Latacunga & 19980825 & SPB $10 \mathrm{~m}$ & Samba & 25 & 1001 & 822 & 810 & 226 & 822 \\
\hline Latacunga & 19980901 & SPB $10 \mathrm{~m}$ & Samba & 48 & 2732 & 2091 & 2119 & 557 & 2091 \\
\hline Latacunga & 19980907 & SPB $10 \mathrm{~m}$ & Samba & 24 & 1305 & 975 & 976 & 279 & 975 \\
\hline Bauru & 20001117 & MIR 45 & Samba/Rumba & 18 & 439 & 203 & 217 & 159 & 203 \\
\hline Bauru & 20001119 & MIR 45 & Samba/Inmarsat & 19 & 1601 & 354 & 402 & 225 & 354 \\
\hline Bauru & 20010213 & MIR 45 & Rumba & 39 & 832 & 507 & 686 & 319 & 507 \\
\hline Bauru & 20010213 & MIR 45 & $\mathrm{SaOz}$ & 39 & 555 & 511 & 484 & 340 & 511 \\
\hline Bauru & 20010213 & MIR 45 & Inmarsat & 39 & 1062 & 1038 & 1048 & 142 & 1038 \\
\hline Bauru & 20010221 & MIR 45 & Samba/Rumba & 48 & 1828 & 1816 & 1817 & 234 & 1816 \\
\hline
\end{tabular}

mereau et al. (2002)) are hot air balloons heated from below by the Earth thermal emission at night and by solar radiation during the day. Therefore, their altitude varies from $26 \mathrm{~km}(20 \mathrm{hPa})$ for the smaller size, $28 \mathrm{~km}(13 \mathrm{hPa})$ for the larger during daytime, to $17 \mathrm{~km}(90 \mathrm{hPa})$ and $24 \mathrm{~km}(30 \mathrm{hPa})$, respectively, at night, depending on the cloud cover, except during the first 3 days of flight before losing the helium when they could fly as high as $34 \mathrm{~km}(4 \mathrm{hPa})$. SPB are constant density (isopycnic) balloons flying between $58 \mathrm{hPa}(19.9 \mathrm{~km})$ and $65 \mathrm{hPa}(19.2 \mathrm{~km})$ depending on the weight of the payload. The SPB flights are described in detail by Vial et al. (2001) and Hertzog and Vial (2001).

Following scientific objectives, balloon capacity and evolution of technology, various payloads are often flown together: always a Samba or Inmarsat service payload of CNES for controlling the flight (cut down if below a prescribed altitude), coupled or not with $\mathrm{H}_{2} \mathrm{O}$ or Rumba scientific payloads of LMD (Laboratoire de Météorologie Dynamique) or the SAOZ of Service d'Aéronomie. All of them are carrying an ARGOS satellite transmitter allowing the transmission of $30-50 \mathrm{kB}$ of data per day, which may be affected sometimes by transmission errors of large amplitude. But in addition, Samba is equipped with a HF system at $15 \mathrm{Mhz}$, replaced in 2000 by a more powerful Inmarsat satel- lite system allowing the transmission of one format of data every $10-15 \mathrm{~min}$. A major technological step in all the payloads is the replacement after 1994 of the ARGOS Doppler localisation system of $\pm 2-5 \mathrm{~km}$ accuracy during the overpass of the satellites 4-5 times per day and the pressure sensor for altitude determination, by a GPS providing 3D location within $100-200 \mathrm{~m}$ as fast as required, further improved to 10-20 m after 2000 .

\subsection{Temperature data}

The measurement of temperature is a difficult task on longduration balloons because of the solar heating of the sensor and its support, as well as of the gondola, little ventilated at low pressure in the stratosphere. Except on the SAOZ payload where the sensor is a Vaisala radiosonde thermocap, those used on all others are Veco aluminised micro-bead thermistors of $250 \mu \mathrm{m}$ mounted on one meter long booms $180^{\circ}$ apart from the gondola (Samba, $\mathrm{H}_{2} \mathrm{O}$ and Inmarsat) or better, but more fragile, hanging $5 \mathrm{~m}$ below (Rumba). They are all calibrated in a thermal chamber, for CNES payloads to within $\pm 0.5^{\circ} \mathrm{C}$, and for LMD payloads to within $\pm 0.2^{\circ} \mathrm{C}$. As an illustration of the difficulty of the measurements, Fig. 1 shows the difference of temperature between the two sensors 

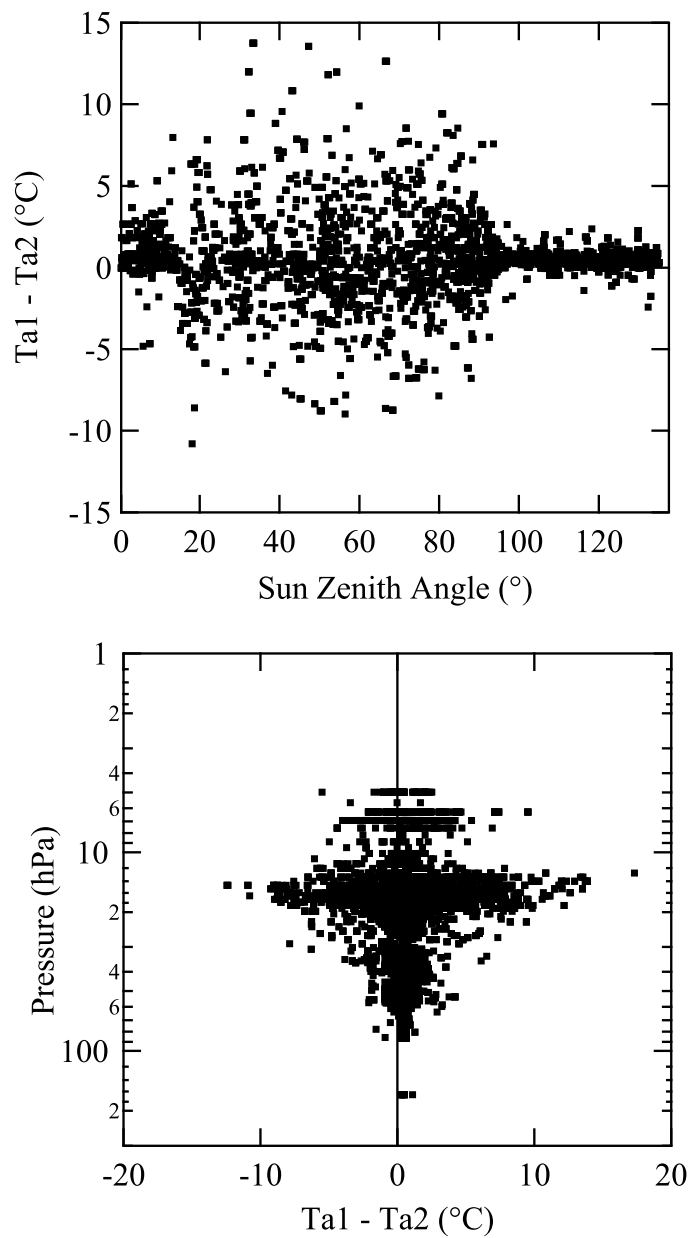

Fig. 1. Difference of temperature readings between two thermistors mounted on $1 \mathrm{~m}$ long booms $180^{\circ}$ apart on the Samba payload (MIR flight of Dec 2, 1988). Upper panel: plotted against solar zenith angle. Lower panel: plotted against pressure.

mounted $180^{\circ}$ apart from the gondola of the 25 day SambaMIR flight of 2 December 1988, plotted against solar zenith angle (upper panel), and pressure (lower panel). The bias of $0.5^{\circ} \mathrm{C}$ remains constant, but the dispersion increases from $\pm 0.4^{\circ} \mathrm{C}$ during nighttime at $\mathrm{SZA}>94^{\circ}$ at altitude levels below $30 \mathrm{hPa}(24 \mathrm{~km})$, to $\pm 7^{\circ} \mathrm{C}$ during daytime at float altitude at $15 \mathrm{hPa}(27 \mathrm{~km})$. Also shown are the drop of dispersion at $\mathrm{SZA}<20^{\circ}$ around noontime when the payload is in the shadow of the balloon, and the measurements at high altitude during the first days of flight, the highest being during the first night after launch. Most of the noise is caused by the heating of the sensor passing in the lee of the rotating payload. The noise is significantly reduced in the Rumba mounting $5 \mathrm{~m}$ below the payload, but the observations display a systematic day-night offset due to the direct heating of the thermistor.

For all above reasons, daytime measurements will be ignored in the following and only nighttime data at SZA $>94^{\circ}$ will be used, with the exception of two Rumba flights in 2001. The data of each flight have been carefully checked by comparison of measurements of all available temperature sensors. Biases never exceed $\pm 0.8^{\circ} \mathrm{C}$ between the two Samba sensors and $\pm 1.2^{\circ} \mathrm{C}$ between those and thermistors of other payloads calibrated independently, with two exceptions: the flight of 14 January 1994 when one of the booms did not deploy correctly, and that of 28 January 1994 displaying large biases likely caused by a confusion of calibration files. Fortunately, temperature measurements are also available in both cases from the $\mathrm{H}_{2} \mathrm{O}$ payload, showing an average difference of $1.1^{\circ} \mathrm{C}$ in the first case, but of $-5^{\circ} \mathrm{C}$ in the second, onto which the Samba data has been normalised. Overall, an accuracy of $\pm 1.2^{\circ} \mathrm{C}$ can be estimated for the full nighttime temperature data set.

\subsection{Position data for winds and trajectories}

In contrast to temperature, the accuracy of wind measurements improved with time with the evolution of technology. It varies from about $\pm 1.5 \mathrm{~m} / \mathrm{s}$ on average for the early data set based on ARGOS Doppler localisations of $\pm 2-5 \mathrm{~km}$ uncertainty 4-5 times per day until 1994 , to $0.15 \mathrm{~m} / \mathrm{s}$ with a scrambled GPS information of $\pm 100 \mathrm{~m}$ accuracy every 15 minutes in 1996 and 1998, to less than $0.01 \mathrm{~m} / \mathrm{s}$ after 2000. Another parameter contributing to the accuracy of wind comparison with ERA-40 is the uncertainty on pressure/altitude. Until 1994, the altitude is derived from pressure measurements at $0.6 \mathrm{hPa}$ resolution within $\pm 1 \mathrm{hPa}$ accuracy. The corresponding altitude error varies from about $\pm 50 \mathrm{~m}$ at $50 \mathrm{hPa}$, the average MIR flight level during nighttime, to $\pm 450 \mathrm{~m}$ at $15 \mathrm{hPa}$ during the day. An average vertical gradient of horizontal wind of $2 \mathrm{~m} / \mathrm{s} / \mathrm{km}$ will thus introduce an additional error of $0.1 \mathrm{~m} / \mathrm{s}$ at $50 \mathrm{hpa}$ and $1 \mathrm{~m} / \mathrm{s}$ at $15 \mathrm{hPa}$. Similarly, the GPS uncertainty $\pm 100 \mathrm{~m}$ in 1996-1998 would introduce an average uncertainty of $0.2 \mathrm{~m} / \mathrm{s}$ dropping to less than $0.04 \mathrm{~m} / \mathrm{s}$ after 2000. Overall, the accuracy of horizontal wind comparisons with ERA-40 at daytime flight level improves from $2.5 \mathrm{~m} / \mathrm{s}$ before 1994 , to $0.17 \mathrm{~m} / \mathrm{s}$ in $1996-1998$ and $0.05 \mathrm{~m} / \mathrm{s}$ after 2000. Finally, depending on the sampling of the localisation system, the number of wind measurements per day varies from 5-6 during the ARGOS period, to about a maximum of 96-144 /day after 1996 depending on the number of Samba $\mathrm{HF}$ ground receiving stations. The number of temperature and localisation data available for each flight is displayed in Table 1. For flights with ARGOS localization (1988-1994), interpolation of the position was done in the digitization process. 23 flights have temperature data, 23 have horizontal wind data and 18 qualify for trajectory comparison: at least 10 days of data with gaps not exceeding 10 hours.

\subsection{ECMWF ERA-40 reanalysis data}

The ECMWF 40 year reanalyses (Uppala et al., 2005) are produced every $6 \mathrm{~h}$ with a T159 model using a 3-D 


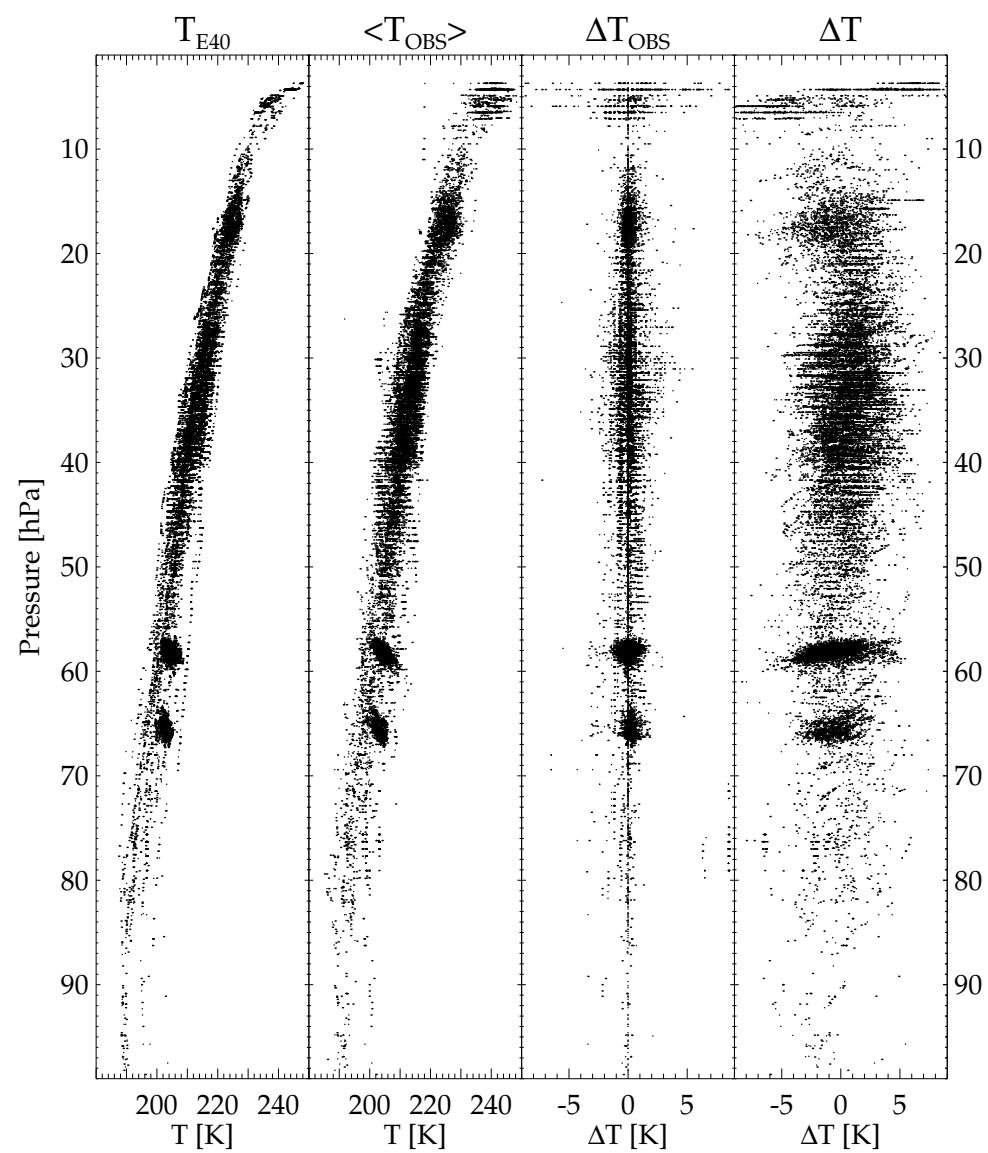

Fig. 2. Temperature comparisons between ECMWF ERA-40 and long-duration balloon measurements. Panel 1 (from left): $T_{\mathrm{E} 40}$. Panel 2: $\left\langle T_{\mathrm{OBS}}\right\rangle$. Panel 3: $\Delta T_{\mathrm{OBS}}=T_{1}-T_{2}$. Panel 4: $\Delta T=T_{\mathrm{E} 40}-\left\langle T_{\mathrm{OBS}}\right\rangle$.

variational assimilation (Courtier et al., 1998). The vertical level spacing in the stratosphere is $1.4 \mathrm{~km}$. We have extracted the data in a $1.5 \times 1.5$ degree latitude-longitude grid from a T79 truncation. The temperatures and horizontal winds from ECMWF ERA-40 are interpolated to the balloon latitude, longitude and pressure using an interpolation procedure which is linear in time and space and log-linear in pressure.

\section{Temperature comparison}

Figure 2 shows the temperatures from the reanalysis, $T_{\mathrm{E} 40}$, the average of the two simultaneously measured temperatures, $\left\langle T_{\mathrm{OBS}}\right\rangle$, the difference between the two measured temperatures, $\Delta T_{\mathrm{OBS}}=T_{1}-T_{2}$, and the temperature differences between ERA-40 and the balloon average measurement, $\Delta T=T_{\mathrm{E} 40}-\left\langle T_{\mathrm{OBS}}\right\rangle$. The many data points where $\Delta T_{\mathrm{OBS}}=0$ are an artifact of setting $T_{2}$ equal to $T_{1}$ for the nine flights where there was only one temperature sensor.

359 data points with an absolute temperature difference $(|\Delta T|)$ greater than $50 \mathrm{~K}$ due to ARGOS transmission errors were discarded, leaving 38623 data points. The mean temperature difference and the standard deviation are: $0.35 \pm 2.6 \mathrm{~K}$. Even with the outliers beyond $\pm 50 \mathrm{~K}$ removed, the data set still exhibits outliers, and the use of median statistics is more robust. The median temperature difference and the $68 \%$ fractile are $0.37 \pm 2.1 \mathrm{~K}$; i.e. $68 \%$ of the data points have an absolute deviation from the median $(0.37 \mathrm{~K})$ of $2.1 \mathrm{~K}$ or less. For the two Rumba fligths in 2001, daytime data is included. If only nighttime measurements are considered, the data sample is 36598 data points and the mean temperature difference and standard deviation are $0.41 \pm 2.6 \mathrm{~K}$ and the median temperature difference and the $68 \%$ fractile are $0.41 \pm 2.0 \mathrm{~K}$.

The data above $10 \mathrm{hPa}$ exhibit more noise, but there are not that many data points, and removing them makes very little change to the overall result. Removing data above $10 \mathrm{hPa}$ leaves a sample of 37527 with median temperature difference and $68 \%$ fractile of $0.38 \pm 2.0 \mathrm{~K}$. If in addition the daytime data for the 2001 Rumba flights are removed, the sample is 35621 with median temperature difference and $68 \%$ fractile of $0.42 \pm 2.0 \mathrm{~K}$.

The dense clusters of data at 58 and $65 \mathrm{hPa}$ in Fig. 2 are from the SPB flights. It can be seen that altitudes in the range 


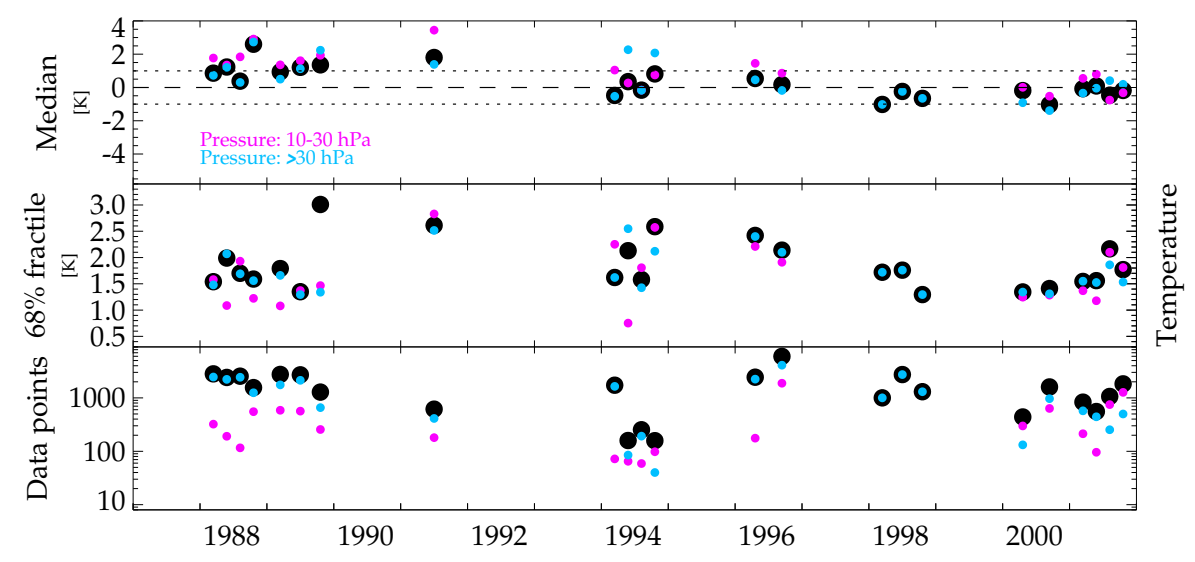

Fig. 3. Statistics for each of 23 long-duration balloon flights. Temperature comparison between ECMWF ERA-40 and balloon measurements. On the X-axis all flights are grouped together year-by-year. Within one year, data points are equidistant regardless of the date of the flight. Big black dots: all available data points for the flight are used. Small red dots: only data points in the height interval 10-30 hPa are used. Small blue dots: only data points in the height interval below $30 \mathrm{hPa}$ are used. Panel 1 (from top): Median of $\Delta T=T_{\mathrm{E} 40}-\left\langle T_{\mathrm{OBS}}\right\rangle$ for each flight. Panel 2: $68 \%$ fractile of $\Delta T$ for each flight. Panel 3: Number of data points for each flight.

65-15 hPa are well covered. Above $8-10 \mathrm{hPa}$ the data dispersion increases drastically.

The statistics for the 23 individual flights is presented in Fig. 3. The $68 \%$ fractiles range from 1.3 to $3.0 \mathrm{~K}$, the largest corresponding to shortest flights. For the longest, there is no significant change of precision between 1998 and 2001, indicating that the improved GPS location/altitude measurements compared to ARGOS/pressure sensor before 1994 has little impact on the results. The high altitude data between $10-30 \mathrm{hPa}$ generally have larger median values than below at pressure larger than $30 \mathrm{hPa}$, except for two flights in 1994, which have few data points $(<100)$. The increased noise on shorter flights (e.g. the 9 days last flight of 1989) is likely the consequence of the higher altitude of the MIR during the first days when still partly inflated with helium. The average median of the temperature difference for the whole period is $0.37 \pm 2.1 \mathrm{~K}$, but there is an indication of a progressive reduction from $1.16 \pm 2.0 \mathrm{~K}$ in $1988-1991$, to $0.26 \pm 2.2 \mathrm{~K}$ in 1994-1996 and $-0.46 \pm 1.7 \mathrm{~K}$ after 1998 , which could translate in an average trend of $-0.13 \pm 0.03 \mathrm{~K} /$ year or $1.9 \mathrm{~K}$ during the 14 year period. Since the temperature sensors and their calibration procedures, moreover carried out at the two independent laboratories, remain the same during the whole period, there is no reason to suspect a systematic experimental drift in the measurements. The average $-0.46 \pm 1.7 \mathrm{~K}$ bias observed after 1998 is fully consistent with ECMWF temperature evaluations in the tropical stratosphere of Gobiet et al. (2005) from 2.5 years of global radio occultation measurements in 2002-2004, showing insignificant bias in the lower stratosphere, with the exception of $-2 \mathrm{~K}$ difference at the tropopause identified by the authors to result from the difference of vertical resolution between the two data sets. $-0.46 \pm 1.7 \mathrm{~K}$ difference between ERA-40 and the balloons is also very consistent with that derived from the comparison of ECMWF with the HIBISCUS balloons in 2004 displaying a cold bias of $-0.9 \pm 1.3 \mathrm{~K}$ (Knudsen et al., 2006). Finally, the trend or step changes since 1988 fully coincide with the observed evolution of the difference at $100 \mathrm{hPa}$ between ERA-40 and radiosondes in the equatorial region from 1991 to 2003 found by Randel et al. (2004). The long-duration balloon data are totally consistent with those of the radiosondes, suggesting that differences with reanalyses, or satellite observations, are to be attributed to models or satellites and not to radiosondes.

The evolution of the difference between balloons and ERA-40 must thus be attributed to ERA-40. Since the reanalysis system has remained constant in time, this result suggests that the model itself is not the cause, but likely the data assimilated. Most of the information used by the model is that of the Microwave Sounding Unit (MSU) onboard the NOAA and TIROS polar orbiting satellites, replaced in May 1998 by the Advanced Microwave Sounding Unit (AMSU), further replaced by ATOVS in July 2001 in NCEP and METO, but not in ERA-40. Intersatellite offsets are known to occur, difficult to fully compensate particularly when changing the instrument type, as well as the method for correcting for drifts in diurnal sampling time because of the drift of the orbit, or the method for correcting calibration drifts associated with the temperature of the hot calibration target (Christy et al., 2003; Karl et al., 2006).

\section{Horizontal wind comparison}

Exactly as for the temperatures, the ECMWF ERA-40 wind fields are interpolated to the balloon position for comparison with the in situ measurements. 


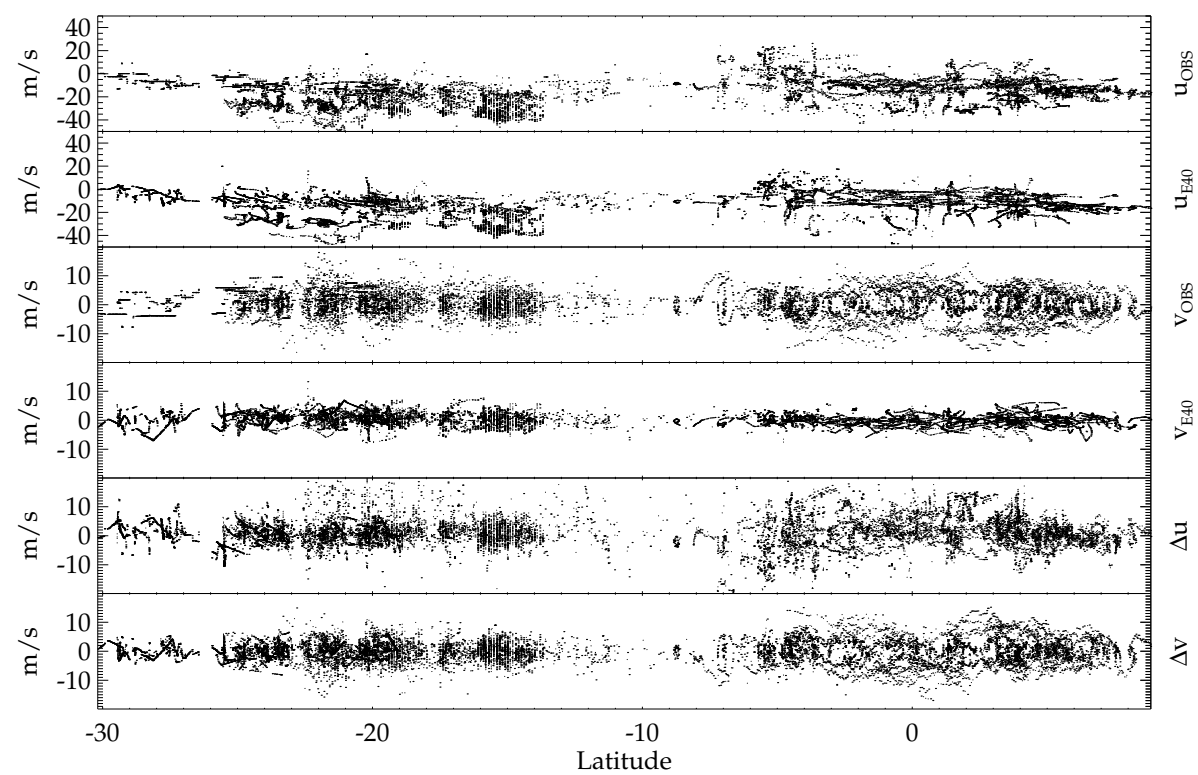

Fig. 4. Horizontal wind comparison between ECMWF ERA-40 and long-duration balloon measurements as a function of latitude. From top to bottom panel: $u_{\mathrm{OBS}}, u_{\mathrm{E} 40}, v_{\mathrm{OBS}}, v_{\mathrm{E} 40}, \Delta u=u_{\mathrm{E} 40}-u_{\mathrm{OBS}}$ and $\Delta v=v_{\mathrm{E} 40}-v_{\mathrm{OBS}}$.

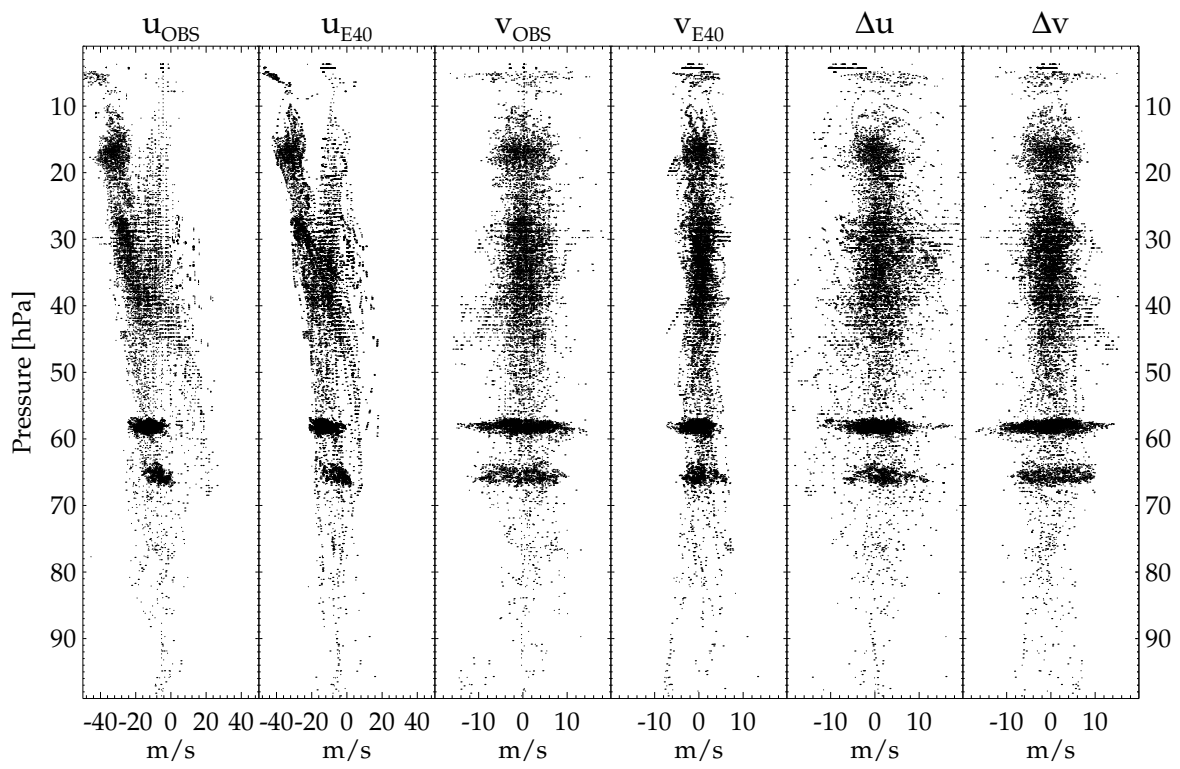

Fig. 5. Horizontal wind comparison between ECMWF ERA-40 and long-duration balloon measurements as a function of altitude. From left to right: $u_{\mathrm{OBS}}, u_{\mathrm{E} 40}, v_{\mathrm{OBS}}, v_{\mathrm{E} 40}, \Delta u=u_{\mathrm{E} 40}-u_{\mathrm{OBS}}$ and $\Delta v=v_{\mathrm{E} 40}-v_{\mathrm{OBS}}$.

Figures 4 and 5 show observed and reanalysed zonal and meridional winds and the difference plotted respectively against latitude and altitude. The data points are not evenly distributed in latitude: the balloons tend to stay within $\pm 8^{\circ}$ of their launch latitude, so that the flights launched from Latacunga from 1991 to 1998 remain in the equatorial region, while those flown from Pretoria in 1988-1989 and Bauru after 2000 stay near the tropic of Capricorn. At the equator, the wind speed varies from $20 \mathrm{~m} / \mathrm{s}$ to $-30 \mathrm{~m} / \mathrm{s}$ depending on the phase of the QBO which is from the west in 1991 and from the east in 1994, 1996 and 1998. Since the flights in the tropics have always been carried out during the summer, the winds are always from the east there, being maximum $(-30 \mathrm{~m} / \mathrm{s})$ in mid-summer, i.e. February 2001 , and minimum $(<10 \mathrm{~m} / \mathrm{s})$ immediately after the turn-around in November in 1988-1989 and 2000. As seen in Fig. 5, the wind speed 


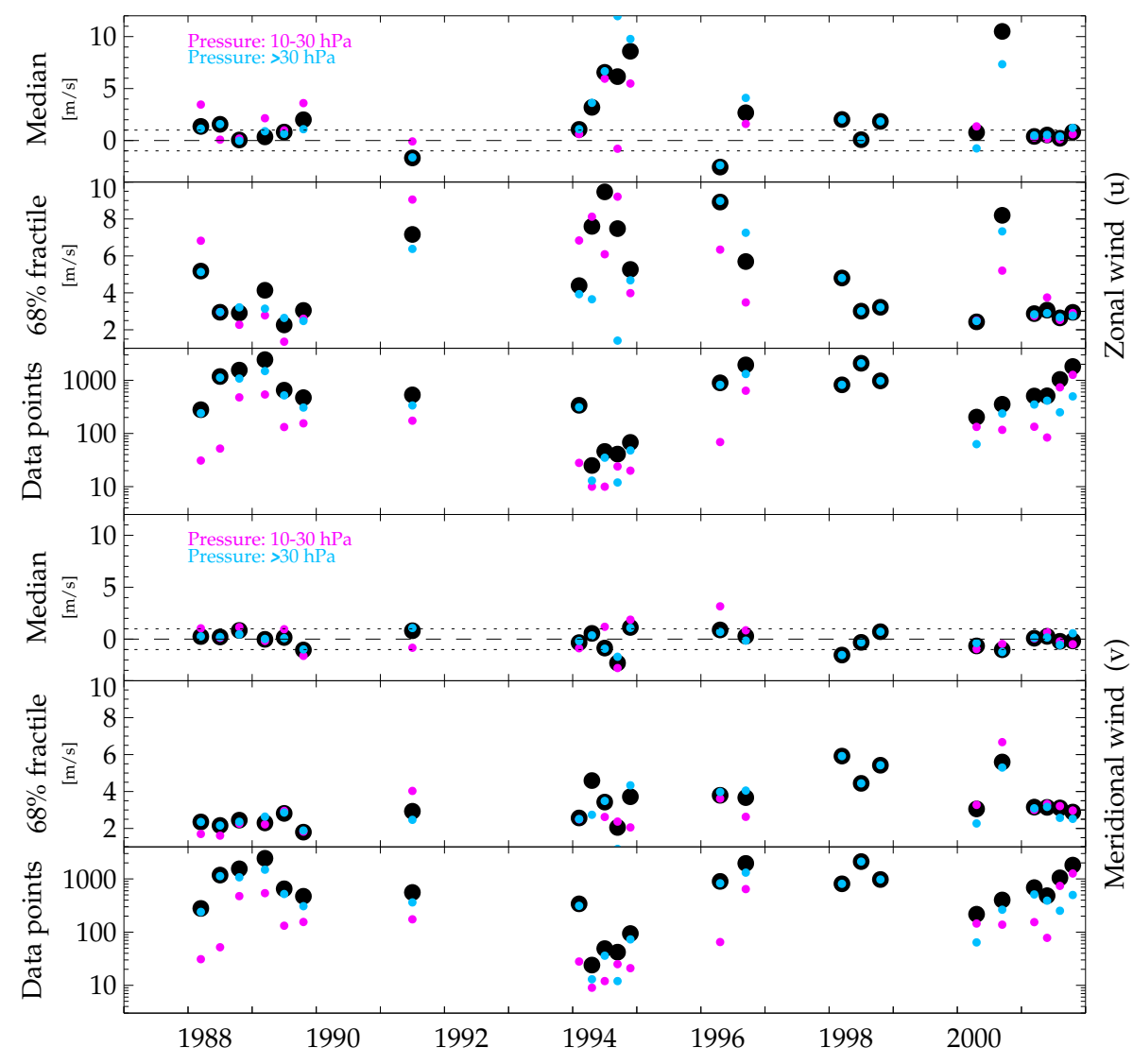

Fig. 6. Statistics for each of 24 long-duration UTLS balloon flights. Horizontal wind comparison between ECMWF ERA-40 and balloon measurements. On the $\mathrm{x}$-axis all flights are grouped together year-by-year. Within one year, data points are equidistant regardless of the date of the flight. Big black dots: all available data points for the flight are used. Small red dots: only data points in the height interval 10-30 hPa are used. Small blue dots: only data points in the height interval below $30 \mathrm{hPa}$ are used. Panel 1 (from top): Median of $\Delta u$ for each flight. Panel 2: $68 \%$ fractile of $\Delta u$ for each flight. Panel 3: Number of u data points for each flight. Panel 4: Median of $\Delta v$ for each flight. Panel 5: $68 \%$ fractile of $\Delta v$ for each flight. Panel 6: Number of $v$ data points for each flight.

increases with altitude when from the east, at the tropics as well at the equator above $40 \mathrm{hPa}$ during the east phase of the QBO when the lower layers are in the west phase. In contrast, in 1991 the winds are blowing from the east at upper levels and from the west lower down.

Figures 4 and 5 show that differences in meridional and zonal winds are larger than the signal in ERA-40 winds, and the problem is more pronounced close to the equator than in the tropics. In the equatorial region there are not enough observations to constrain the model. The radiosounding network is quite sparse at low latitudes and most of the stations are located over land (and mainly in South-East Asia), and space-borne temperature (or radiance) observations cannot be used close to the equator to constrain the wind field.

The statistics for individual flights are displayed in Fig. 6 Overall, there are 18794 data points displaying an average difference of $1.05 \pm 5.0 \mathrm{~m} / \mathrm{s}$ with ERA-40 for the zonal wind $(0.82 \pm 3.9 \mathrm{~m} / \mathrm{s}$ for median and $68 \%$ fractile) and $-0.04 \pm 3.6 \mathrm{~m} / \mathrm{s}(0.01 \pm 3.2 \mathrm{~m} / \mathrm{s})$ for the meridional compo- nent. The absolute difference and $68 \%$ fractile are larger at the equator $(1.00 \pm 5.1 \mathrm{~m} / \mathrm{s})$ than in the tropics $(0.71 \pm 3.2 \mathrm{~m} / \mathrm{s})$ for the $u$ component, as well as for the $v$ component $0.01 \pm 4.2 \mathrm{~m} / \mathrm{s}$ and $0.01 \pm 2.6 \mathrm{~m} / \mathrm{s}$. Overall, there is an absolute positive bias for the ERA-40 zonal wind at both the equator and the tropics, however relatively small (5-10\%) in reference to the average speed.

This picture is also seen in Fig. 6 for the individual flights where all median values for the zonal component are positive except for two flights: 19910403 and 19960328. The first is when the QBO index was west at both 30 and $50 \mathrm{hPa}$, and the second was when the index was west at 30 , but east at $50 \mathrm{hPa}$, suggesting also a positive bias of ERA-40 in east phase QBO. The largest median values and 68\% fractile are observed in the three last equatorial flights of 1994 of relatively short duration (8, 9 and 7 days) and thus at higher average altitude than others; on the 1994 flights where the wind at low latitude during night-time was also from the east; and on the flight of 20001119 launched in light stratospheric 

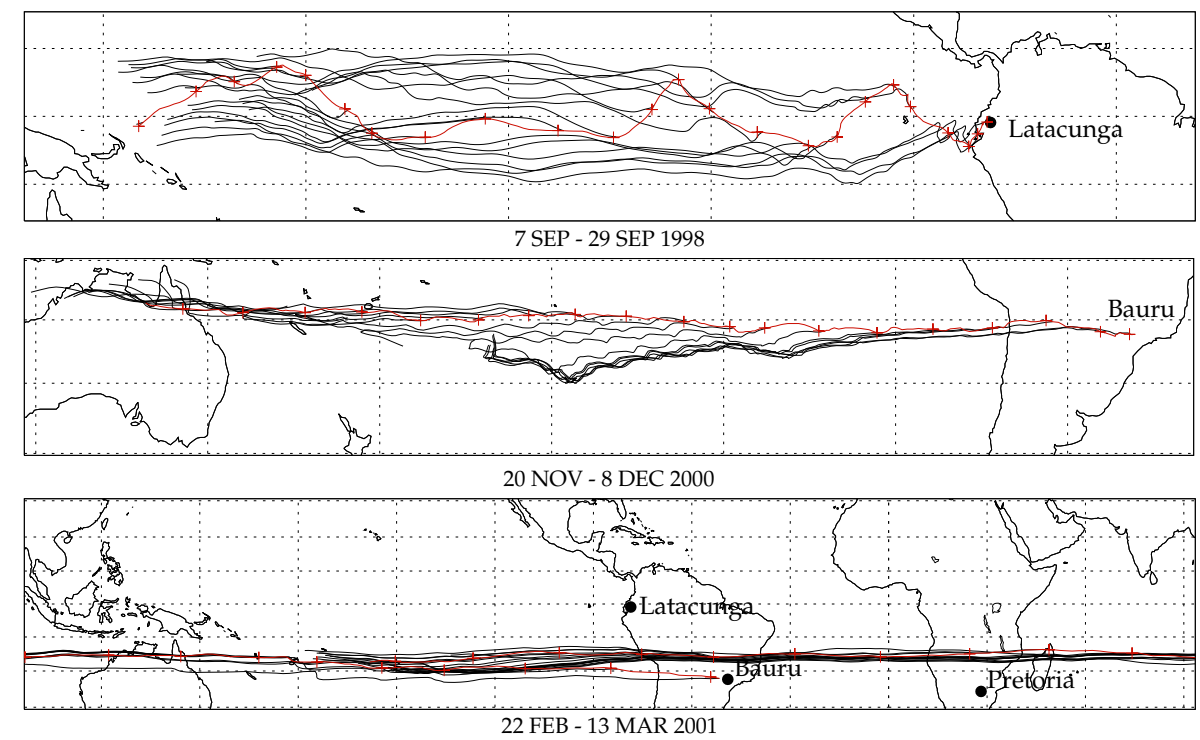

Fig. 7. Trajectories for three flights: 19980907, 20001119 and 20010221. Balloon positions are shown in red. ECMWF ERA-40 trajectories were started every $2 \mathrm{~h}$; for clarity, only every 12th trajectory (black lines) is shown; the starting points are shown with red plusses. The geographical grids show every 10 degrees in latitude and every 30 degrees in longitude.

wind immediately after the turn-around and thus travelling very slowly in 19 days across the Pacific. Note that this flight is also the one showing the largest dispersion of the meridional component at the tropics. At the equator, the largest deviations of the meridional component are observed on the three constant level balloons around 19-20 km where the trajectories are showing relatively large meridional oscillations associated with waves poorly captured by ERA- 40 . When flights are performed close to the QBO shear, a small shift in ERA-40 QBO phase may produce large discrepancies in the comparison to the zonal wind observations, which may be the case for the 1996 flights.

The amplitude and deviations reported here are larger than that observed between the rawinsondes/rocketsondes and ERA-40 by Baldwin and Gray (2005) displaying excellent agreement between model and observations in monthly mean amplitude and standard deviations of less than $1.4 \mathrm{~m} / \mathrm{s}$ after 1985 and less than $1.0 \mathrm{~m} / \mathrm{s}$ after 1995 . The smaller dispersion of monthly averages compared to this work might indicate that most of the discrepancy observed here might be due to atmospheric variations of periods shorter than one month not well resolved by ERA-40. Besides inertia gravity waves, part of the explanation could come from planetary waves trapped in the equatorial wave guide, i.e. Kelvin and Rossby waves like those reported by Hertzog and Vial (2001). Finally, the average high bias of ERA-40 of $0.71 \pm 3.2 \mathrm{~m} / \mathrm{s}$ found here in the tropics between $10^{\circ}-30^{\circ} \mathrm{S}$ is very similar to the average difference of $0.7 \mathrm{~m} / \mathrm{s}$ between ECMWF and the HIBISCUS balloons in 2004 found by Knudsen et al. (2006) in the same latitude range.
Overall, the comparison of wind speed derived from longballoon flights since 1988 to the ERA-40 reanalysis suggests a permanent slight systematic high bias in the zonal component in the model of $0.7 \mathrm{~m} / \mathrm{s}$ in the tropical summer stratospheric easterlies and $1 \mathrm{~m} / \mathrm{s}$ at the equator during the East phase of the QBO. However, when compared to the absolute wind speed of $10-20 \mathrm{~m} / \mathrm{s}$, the relative bias remains limited, not exceeding 5-10\%. Finally, no significant bias has been observed in the meridional component either at the tropics or at the equator, but a relatively large dispersion of the order $\pm 4 \mathrm{~m} / \mathrm{s}$ likely due to waves of different periods not fully captured by the model.

\section{Trajectory comparison}

Trajectories were calculated with a 2nd order Runge-Kutta integration scheme with a time step of $30 \mathrm{~min}$ for the SPB and $10 \mathrm{~min}$ for the MIR balloons. Along the balloon flight track new trajectories were started every 2 hours. The SPB trajectories were forced to be isopycnic, whereas the MIR trajectories were forced to follow the pressure measured on board the balloon. In Fig. 7 are shown trajectories for three representative, but (for clarity) fairly short flights. The top panel shows the 19980907 flight path at the equator which, as the other two 1998 flights, also at the equator (trajectories not shown), exhibits meridional displacements likely caused by Rossby-gravity waves (see Vial et al. (2001) and Hertzog and Vial (2001) which give detailed analyses of the dynamics of the lower stratosphere during these three SPB flights). The middle panel of Fig. 7 shows the 20001119 MIR flight 


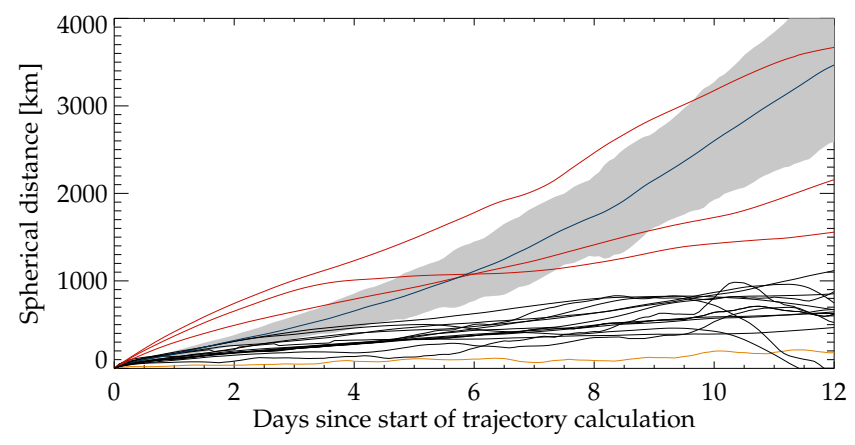

Fig. 8. Mean trajectory errors for 18 flights compared to ECMWF ERA-40. The red lines are the three equatorial SPB flights of 1998 (19980907 has the smallest error after 12 days). The yellow line correspond to the longest flight: the 19881208 Pretoria launch. The blue line is the 20001119 flight from Bauru, and for this flight the $68 \%$ confidence limits are indicated by the shaded area.

in the tropics during the spring turn-around period crossing the Pacific in 19 days which exhibits the largest trajectory errors, in contrast to the fast zonal 20010221 flight in the midsummer (shown in the lower panel), crossing the Pacific in 5-6 days. The flights launched from Pretoria earlier in the season in November-December 1988 and 1989 during the growing phase of stratospheric easterlies tend to drift gradually equatorward. The 1991 flight, the only one launched when the QBO was in its westerly phase at $30 \mathrm{hPa}$, drifted first slowly westward when still at high altitude, then stayed for 12 days near $180^{\circ}$ over the central Pacific, drifting westward at $15 \mathrm{hPa}$ during daytime and back eastward at $60 \mathrm{hPa}$ at night.

For each trajectory, the spherical distance between the observed and calculated trajectories was calculated as a function of time since the trajectory start point. For each of the 18 flights for which trajectory comparisons were carried out, the average distance as a function of time is plotted in Fig. 8. The three 1998 SPB flights at $19-20 \mathrm{~km}$ stayed within $9^{\circ}$ latitude of the equator, resulting in larger errors than that of the MIRs above in the lower stratosphere. The Bauru flight from 20001119, depicted by a blue line in Fig. 8, travelling in the light wind latitude region at the northern border of the stratospheric sub-tropical jet, also encountered waves that were not well described by ECMWF. In Fig. 9 the mean errors after 5, 10 and 12 days are shown for each of the individual flights. Error bars show the $68 \%$ confidence intervals which are calculated taking into account the lag one serial correlation by using Jones (1975, Eq. (2.14)) for a stationary Markov process. For a flight with fairly large error bars, 20001119, the $68 \%$ confidence interval is also pictured by the shaded area in Fig. 8. The largest errors of $1200-1500 \mathrm{~km}$ after 5 days are observed on the three constant-level balloons in 1998 near the tropopause, the error being significantly smaller on all MIR flights at higher altitude in the stratosphere in the tropics as well as at the equator.

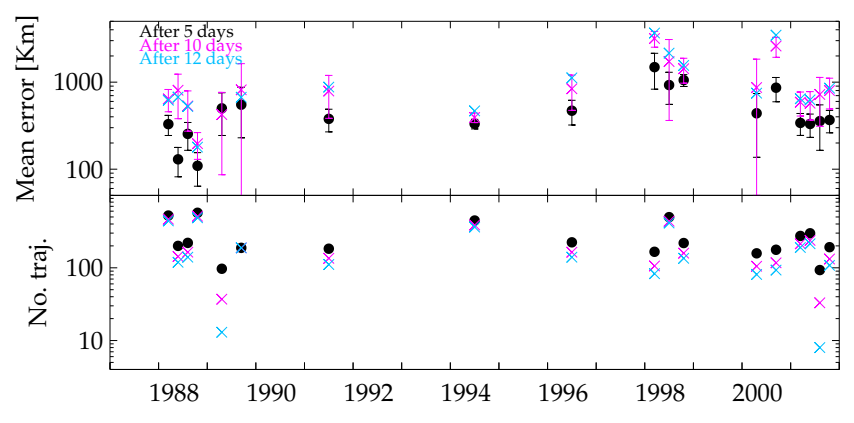

Fig. 9. Statistics for each of 18 long-duration balloon flights. Trajectory comparison between ECMWF ERA-40 and balloon measurements. On the $\mathrm{x}$-axis all flights are grouped together year-byyear. Within one year, data points are equidistant regardless of the date of the flight. Black dots: Mean spherical distance after 5 days. $68 \%$ confidence interval indicated by black error bars. Red crosses: Mean spherical distance after 10 days. $68 \%$ confidence interval indicated by blue error bars. Blue crosses: Mean spherical distance after 12 days. $68 \%$ confidence interval indicated by red error bars. Panel 1 (from top): Mean error of ERA-40 trajectories. Panel 2: Number of trajectories.

An overall variance for the combined data set of 18 individual results is simply found by summing the variances and dividing by the number of flights, since the flights are considered independent. Combining the results from the 18 independent flights, reduces the variance of the errors considerably: Overall, we find mean ERA-40 trajectory errors for the 18 flights of $512 \pm 57 \mathrm{~km}$ after 5 days, $995 \pm 131 \mathrm{~km}$ after 10 days and $1047 \pm 157 \mathrm{~km}$ after 12 days.

This compares well with the results of Knudsen et al. (2006) who find trajectory errors in SPB and MIR flights at the tropics of about $500 \mathrm{~km}$ after 5 days for tropical and southern mid-latitude long-duration balloon flights in 2004 as compared to operational ECMWF analyses.

\section{Conclusions}

The temperature and wind of the ECMWF ERA-40 reanalysis in the tropical lower stratosphere during the period 19882001 have been evaluated by comparison with independent in situ measurements of 21 IR Montgolfier and superpressure long-duration balloon flights performed by CNES from Pretoria $\left(26^{\circ} \mathrm{S}\right)$ in South Africa in 1988-1989, Latacunga $\left(1^{\circ} \mathrm{S}\right)$ in Ecuador in 1991-1998 and Bauru $\left(22^{\circ} \mathrm{S}\right)$ in Brazil in 2000-2001. Compared to that of the balloons, the ERA40 temperature displays a bias varying progressively from $+1.16 \mathrm{~K}$ in $1988-1989$, to $+0.26 \mathrm{~K}$ in $1994-1996$ and $-0.46 \mathrm{~K}$ after 1998 , the latter being fully consistent with recent evaluations of ECMWF operational analysis from radio occultation and in situ long-duration balloon observations. The amplitude of the bias and its evolution are very similar to the results of a previous evaluation from radiosondes in 
1991-2003. The similarity of the difference with radiosondes and long-duration balloons suggests that the origin of the drift of ERA-40 might be mainly due to errors in the series of satellite measurements of MSU and AMSU since 1998 assimilated in the model.

The ERA-40 zonal wind speed in the lower stratosphere appears slightly overestimated by $0.7-1.0 \mathrm{~m} / \mathrm{s}$ in both the summer tropical easterlies and in the equatorial QBO associated alternative westerlies and easterlies, that is by $5-10 \%$ compared to the average $10-20 \mathrm{~m} / \mathrm{s}$ wind speed. This bias, fully consistent with a recent evaluation of ECMWF operational analysis in 2004, is found constant during the whole 1988-2001 period suggesting a shortfall in the variabililty of ERA-40 horizontal winds in the lower stratosphere in the tropics and the equatorial region.

Finally the calculated trajectories using ERA-40, frequently used for analysing field observations, are found in error compared to that of the balloons by $\pm 500 \mathrm{~km}$ after 5 days and $\pm 1000 \mathrm{~km}$ after 10 days.

Acknowledgements. We thank ECMWF for providing the ERA-40 reanalysis. This work was supported by the 5th European Commission Framework Programme through the HIBISCUS project, contract no. EVK2-2001-00055, the EC Framework Programme 6 through the SCOUT-O3 project, contract no. GOCE-CT-2004505390 and The Danish Research Council for Technology and Production Sciences through the Calisto project.

Edited by: R. MacKenzie

\section{References}

Baldwin, M. P. and Gray, L. J.: Tropical stratospheric zonal winds in ECMWF ERA-40 reanalysis, rocketsonde data, and rawinsonde data, Geophys. Res. Lett., 32, L09 806, doi:10.1029/2004GL022 328, 2005.

Christy, J. R., Spencer, R. W., Norris, W. B., Braswell, W. D., and Parker, D. E.: Error Estimates of Version 5.0 MSU/AMSU Bulk Atmospheric Temperatures, J. Atmos. Oceanic Tech., 20, 613629, 2003.

Courtier, P., Andersson, E., Heckley, W., Pailleux, J., Vasiljevic, D., Hamrud, M., Hollingsworth, A., and Fisher, M.: The ECMWF implementation of three-dimensional variation assimilation (3DVar), Q. J. Roy. Meteor. Soc., 124, 1783-1807, 1998.

Gobiet, A., Foelsche, U., Steiner, A. K., Borsche, M., Kirchengast, G., and Wickert, J.: Climatological validation of stratospheric temperatures in ECMWF operational analyses with CHAMP radio occultation data, Geophys. Res. Lett., 32, L12806, doi:10.1029/2005GL022 617, 2005.

Hertzog, A. and Vial, F.: A study of the dynamics of the equatorial lower stratosphere by use of ultra-long-duration balloons, 2 . Gravity waves, J. Geophys. Res., 106, 22 745-22 762, 2001.

Hertzog, A., Basdevant, C., and Vial, F.: An assessment of ECMWF and NCEP/NCAR reanalyses in the southern hemisphere at the end of the pre-satellite era: Results from the EOLE experiment (1971-1972), Mon. Wea. Rev., 134, 3367-3383, 2006.
Jones, R. H.: Estimating the Variance of Time Averages, J. Appl. Meteor., 14, 159-163, 1975.

Karl, T. R., Hassol, S. J., Miller, C. D., and Murray, W. L. (Eds.): Temperature Trends in the Lower Atmosphere: Steps for Understanding and Reconciling Differences. A report by the Climate Change Science Program and the Subcommittee on Global Change, Climate Change Science Program and the Subcommittee on Global Change, Washington, DC, 2006.

Knudsen, B. M., Pommereau, J.-P., Garnier, A., NunesPinharanda, M., Denis, L., Newman, P., Letrenne, G., and Durand, M.: Accuracy of analyzed stratospheric temperatures in the winter Arctic vortex from infrared Montgolfier longduration balloon flights 2. Results, J. Geophys. Res., 107(D20), doi:10.1029/2001JD001 329, 2002.

Knudsen, B. M., Christensen, T., Hertzog, A., Deme, A., Vial, F., and Pommereau, J.-P.: Accuracy of analysed temperatures, winds and trajectories in the Southern Hemisphere tropical and midlatitude stratosphere as compared to long-duration balloon flights, Atmos. Chem. Phys., 6, 5391-5397, 2006,

http://www.atmos-chem-phys.net/6/5391/2006/.

Pommereau, J.-P., Garnier, A., Knudsen, B. M., Letrenne, G., Durand, M., Nunes-Pinharanda, M., Denis, L., Vial, F., Hertzog, A., and Cairo, F.: Accuracy of analyzed stratospheric temperatures in the winter Arctic vortex from infrared Montgolfier long-duration balloon flights 1 . Measurements, J. Geophys. Res., 107(D20), doi:10.1029/2001JD001 379, 2002.

Pommereau, J.-P., Garnier, A., Held, G., Gomes, A.-M., Goutail, F., Durry, D., Borchi, F., Hauchecorne, A., Cocquerez, P., Letrenne, G., , Vial, F., Hertzog, A., Legras, B., Pisso, I., Pyle, J. A., Harris, N. R. P., Jones, R. L., Robinson, A., Hansford, G., Eden, L., Gardiner, T., Knudsen, B. M., Larsen, N., Nielsen, J. K., Christensen, T., Cairo, F., Pirre, M., Marécal, V., Huret, N., Rivière, E., Coe, H., Grosvenor, D., Edvardsen, K., Donfrancesco, G. D., Ricaus, P., Longo, K., and Freitas, S.: An overview of the HIBISCUS campaign, Atmos. Chem. Phys. Discuss., 7, 2389-2475, 2007, http://www.atmos-chem-phys-discuss.net/7/2389/2007/.

Randel, W. J., Wu, F., , Oltmans, S. J., Rosenlof, K., and Nedoluha, G. E.: Interannual Changes of Stratospheric Water Vapor and Correlations with Tropical Tropopause Temperatures, J. Atmos. Sci., 61, 2133-2148, 2004.

Uppala, S. M., Kållberg, P. W., Simmons, A. J., Andrae, U., da Costa Bechtold, V., Fiorino, M., Gibson, J. K., Haseler, J., Hernandez, A., Kelly, G. A., Li, X., Onogi, K., Saarinen, S., Sokka, N., Allan, R. P., Andersson, E., Arpe, K., Balmaseda, M. A., Beljaars, A. C. M., van de Berg, L., Bidlot, J., Bormann, N., Caires, S., Chevallier, F., Dethof, A., Dragosavac, M., Fisher, M., Fuentes, M., Hagemann, S., Hólm, E., Hoskins, B. J., Isaksen, L., Janssen, P. A. E. M., Jenne, R., McNally, A. P., Mahfouf, J. F., Morcrette, J. J., Rayner, N. A., Saunders, R. W., Simon, P., Sterl, A., Trenberth, K. E., Untch, A., Vasiljevic, D., Viterbo, P., and Woollen, J.: The ERA-40 re-analysis, Q. J. Roy. Meteor. Soc., 131, 2961-3012, 2005.

Vial, F., Hertzog, A., Mechoso, C. R., Basdevant, C., Cocquerez, P., Dubourg, V., and Nouel, F.: A study of the dynamics of the equatorial lower stratosphere by use of ultra-long-duration balloons, 1. Planetary scales, J. Geophys. Res., 106, 22 725-22 744, 2001. 